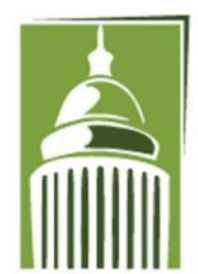

AR F
Global Proceedings Repository

American Research Foundation

ISSN 2476-017X
شبكة المؤرمُات العر.بة

http://arab.kmshare.net/

Available online at http://proceedings.sriweb.org

The 10th International Scientific Conference

Under the Title

"Geophysical, Social, Human and Natural Challenges in a Changing Environment"

$$
\begin{aligned}
& \text { المؤتمر العلمي الدولي العاشر } \\
& \text { تحت عنوان "التحديات الجيوفيزيائية والاجتماعية والانسانية والطبيعية في بيئة متغيرة" } \\
& 25 \text { - } 26 \text { يوليو - تموز } 2019 \text { - اسطنبول - تركيا }
\end{aligned}
$$

http://kmshare.net/isac2019/

\title{
رسوم الوزارة وجوانب من حياة الوزير في العصر العباسي الأول
}

Ministry fees and aspects of the minister's life during the first Abbasid period

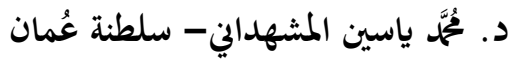

\section{الملخص}

عند قيام الدولة العباسية اهتم خلفاؤها منذ فجر تأسيس سلطاها، بترتيب الدولة وتأسيها وتنظيماها ترتيباً جديداً يعتمد على الإصلاح والقوة ويكاد يكون النظام الإداري للدولة العباسية، هو النظام الإداري السابق الذي وجد في أواخر عهد بني أمية، إلا ما أحدثه العصر الجديد مـن نظم وتراتيب استقاها من التراتيب الإدارية الأعجمية، أو الأنظمة السياسية للدولة "الكسروية"، وأن الخلفـاء العباسيين الأوائل عززوا وظيفة الوزير وثبتوا مركزه ولقبه وخولوه سلطاناً واسعاً وجعلوه المشرف الأعلى على وظائف الدولة وتوجيه سياستها، وهذا لم يكن معروفاً في العصر الأموي، حيث نرى أن الأمويين كانوا عرباً في تفكيرهم، فلم يريدوا أن يدخلوا في نظمهم شيئاً فارسياً وأنفوا أن يقلدوا الفرس في ذلك، ومن هنا وجد من يعمل عمل الوزير وإن لم يأخذ اسمه وعلى هذا الأساس يتبين لنا أن الوزير وقتئذ ما كان إلا مدوناً لما يمليه عليه الخليفة، ويبعث به إلى الأقاليم، وينفذ أوامره ويتقيد بإرشاداته، أما في العهد العباسي فنظام الوزارة ذو سلطان واسع ، وإشراف تام على مرافق الدولة ومؤسساتها كافة، وظهرت مراسيم خاصة في تقليد الوزير، وكان راتب الوزير في العصر العباسي الأول 


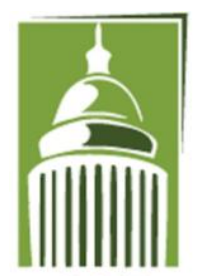

A R F

\section{Global Proceedings Repository \\ American Research Foundation}

ISSN 2476-017X

Available online at http://proceedings.sriweb.org

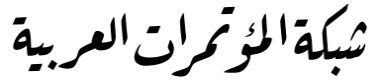

http://arab.kmshare.net/

$$
\begin{aligned}
& \text { يختلف باختلاف فترات هذا العصر وباختلاف الأشخاص، وقد منح الخلفاء العباسيون منذ قيام دولتهم ألقاباً فخرية، كما حدد اللباس } \\
& \text { الرسمي للوزير، وكان يتخذ داره في أفضل بقعة من بغداد، وكان للوزير دار مفردة في دار المخليفة يجلس فيها وينظر في الأعمال، وكان } \\
& \text { موضع احترام وتبجيل من جانب الحاشية، وكان له حرس خاص إضافة إلى الحندم والحجاب الذين كانوا يكيطون به. } \\
& \text { الكلمات المفتاحية: الوزير، العصر العباسي الأول ، رسوم الوزير، حياة الوزير. }
\end{aligned}
$$

\title{
Ministry fees and aspects of the minister's life during the first Abbasid period
}

Dr. Muhamad Yasin Mahmud Almshhadani

\begin{abstract}
When the Abbasid state took care of its successors since the dawn of the establishment of its authority, the order of the state, its establishment and its organization is a new arrangement based on reform and strength. The administrative system of the Abbasid state is the former administrative system found in the late Umayyad era. And the first Abbasid Caliphs strengthened the position of the minister, established his position and title, gave him wide authority, and made him the supreme supervisor of the functions of the state and directing its policy. This was not known in the Umayyad era, The Umayyads were Arabs in their thinking, they did not want to enter into their systems something Persian and did not imitate the Persians in it, and hence found the work of the minister and if he did not take his name and on this basis we find that the minister at that time was only a dictator dictated by the Caliph, The minister's salary during the first Abbasid period varies according to the different periods of this age and the different people. Since the establishment of the Abbasid caliphs, The minister had a single house in the Caliph's house where he sat and looked at the works. He was respected and revered by the footnote. He had his own guard, in addition to the servants and the hijab who were Surround him eind qiam aldawlat aleabbasiat ahtm khlfawha mundh fajar tasis sltanha, btrtyb aldawlat wtasyha wtnzymatha trtybaan jdydaan yaetamid ealaa al'iislah walquat wykad yakun alnizam al'iidarii lildawlat alebasyt, hu alnizam al'iidarii alssabiq aldhy wujid fi 'awakhi.
\end{abstract}

Keywords: minister, first Abbasid period, minister's fees, minister's life. 


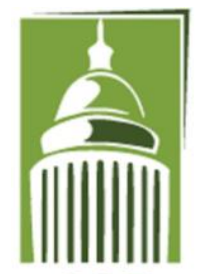

A R F
Global Proceedings Repository

American Research Foundation

ISSN 2476-017X
شبكةالمؤتمرات العربية

http://arab.kmshare.net/

Available online at http://proceedings.sriweb.org

المدخل

اهتم خلفاء الدولة العباسية ، بترتيب الدولة وتأسيها وتنظيماتا ، وقد كان الدور الذي لعبه وزراء هذا العهد نتائج في مجرى الأحداث، وأن قوة الخلفاء في هذا العصر كانت تحد من سلطة الوزراء، وقد اتبعت مراسيم خاصة في تقليد الوزير، وما كان يتمتع به من مكانة مرموقة بين الحاشية، وكان يساعد الوزير في أعبائه عدد من الكتاب يملي عليهم بعض أعماله المراد تنفيذها.

أهمية البحث: الكشف عن المكانة السياسية والاجتماعية للوزير في الدولة العباسية وكيفية تقسيم الأمور الإدارية بحسب ما يقوم به الوزير للتخفيف من الأعباء التي تقع على كاهل الخنليفة.

أهداف البحث: تكمن في تبيان التقاليد التي اتبعت في تقليد الوزير والمراسيم التي تصدر من الخليفة كما تبين الحياة الاجتماعية للوزير بعد تقلده المنصب.

هيكل البحث: احتوى البحث إضافة إلى المقدمة والخاتمة وقائمة المصادر والمراجع النحو الآتي:

$$
\begin{aligned}
& \text { المبحث الأول: الوزير. } \\
& \text { المطلب الأول: مراسيم تقليد الوزير. } \\
& \text { المطلب الثاني: راتب الوزير وثروته. } \\
& \text { المطلب الثالث: ألقاب الوزير. } \\
& \text { المبحث الثاني: حياة الوزير. } \\
& \text { المطلب الأول: زي الوزير. } \\
& \text { المطلب الثاني: دار الوزير. } \\
& \text { المطلب الثالث: مقر عمل الوزير. } \\
& \text { المطلب الرابع: مظاهر تشريف الوزير. }
\end{aligned}
$$




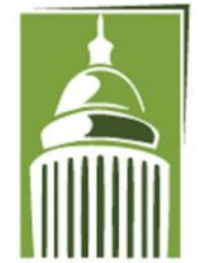

AR F
Global Proceedings Repository

American Research Foundation

ISSN 2476-017X
شبكة المؤرمُات العر.بة

http://arab.kmshare.net/

Available online at http://proceedings.sriweb.org

المبحث الأول : الوزارة :المطلب الأول: مراسيم تقليد الوزير.

ذكر الجهشياري أنه لما عزم المنصور على تقليد الربيع بن يونس الوزارة والعرض أمره بالجلوس في بيته حتى يأتيه رسوله فاغتم الربيع

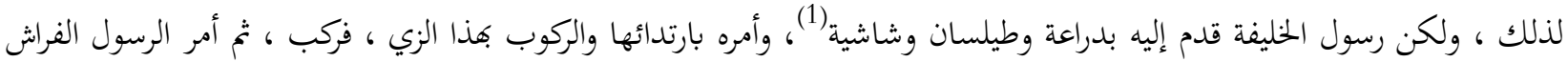
أن يطرح له مرفقه تحت البساط، تقصيرا به عن منزلة المهدي وعيسى بن علي ، إذ كان يطرح لمما مرفقتين ظاهرتين. فلما وصل الربيع

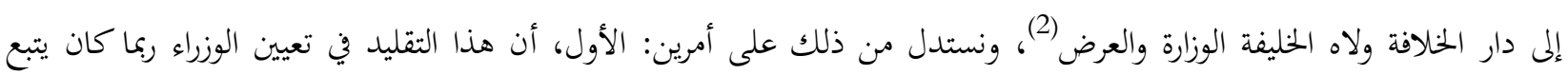
لأول مرة لأن الربيع اغتم في أول الأمر عندما طلب منه الخليفة انتظار رسوله إليه فلو كان هذا التقليد متبعا من قبل لما جزع الربيع ،

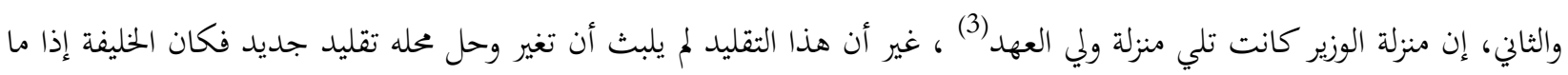
رشح شخصا للوزارة أرسل إليه بعض كبار الموظفين أو الحجاب فيستدعي إلى دار الحليفة ثم ييلغ قرار الاختيار ويخلع عليه خلع الوزارة أمام غرفة باب الخليفة وبمحضر من أرباب المناصب ، ثم يقدم له عندما يخرج من الدار فرس من خيل الخليفة ليمتطيه ويتوجه به إلى دار الوزارة راكبا ونسخة لعهد منشورة بين يديه وجميع أرباب الدولة مشاة بين يديه، فيجلس في دست الوزارة بالديوان ثم يقرأ عهده

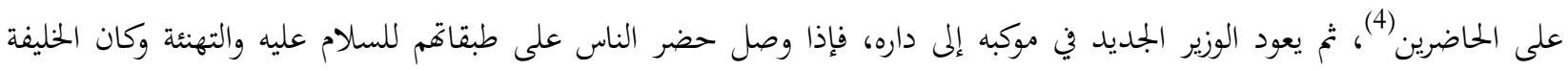

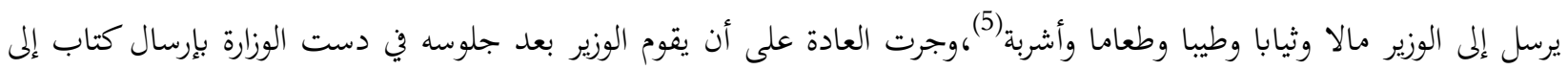
دار الخلافة

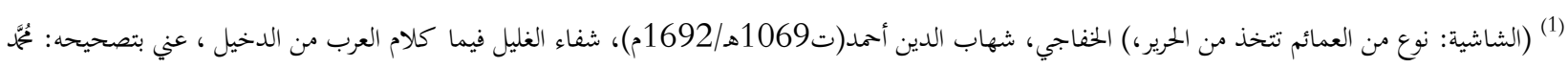

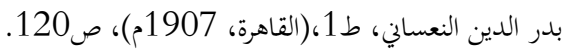

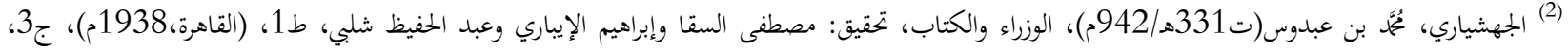

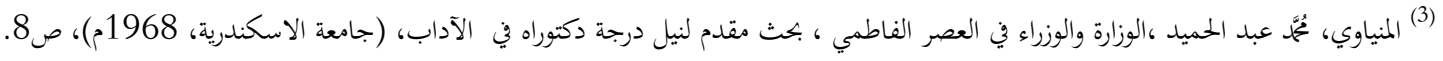

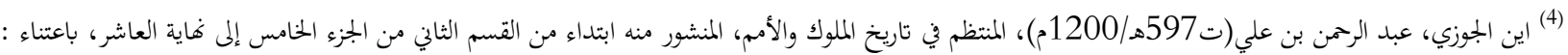

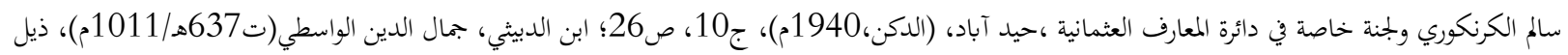

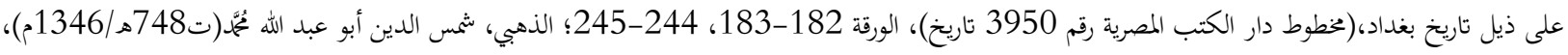

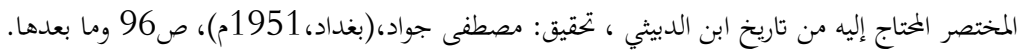

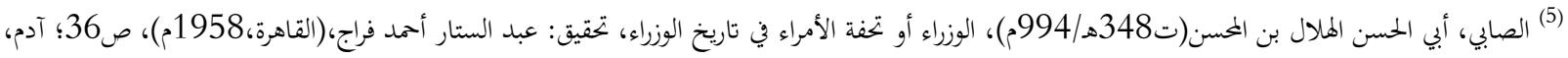

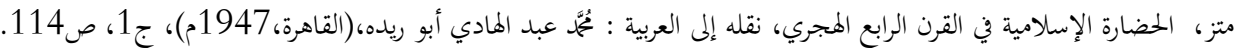




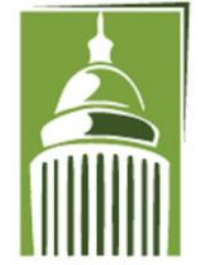

AR F
Global Proceedings Repository

American Research Foundation

ISSN 2476-017X

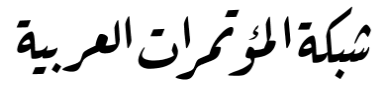

http://arab.kmshare.net/

Available online at http://proceedings.sriweb.org

يتضمن الدعاء والثناء للخليفة واعلامه بعقوده وتسلمه منصبه (6) وكان الخليفة يجيب على نفس الكتاب الذي يرفعه الوزير بخطه دليلا على اطلاعه عليه وتأييده له، وكان الخليفة يختار وزرائه عادة من الذين تمرسوا في أعمال الدواوين(1) ،كذلك جرت العادة عندما يعزم الخليفة على اختيار شخص ما لمنصب الوزارة أن يسجل حينئ عقدا يوقعه كل من الطرفين المتفقين وتختلف صيغة العقد باختلاف درجة المنصب(2) ، ويبدو أيضا أن الوزير هو الذي كان يضع صيغة المرسوم ويثبت الشرائط التي يريد تحقيقها والتي جرى التفاوض

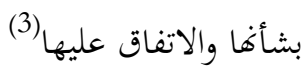
المطلب الثاني: راتب الوزير وثروته. راتب الوزير وثروته: كان راتب الوزير في العصر العباسي الأول يختلف باختلاف فترات هذا العصر وباختلاف الأشخاص فكانت رواتب الكتاب والعمال منذ قيام الدولة العباسية حتى خلافة المأمون بتري على النحو الذي كانت معروفة عليه في العصر الأموي، وقد وصل هذا الراتب إلى ثلاثة مائة دينار غير أن هذا الراتب لم يلبث أن تعرض للزيادة منذ أن تولى الفضل بن سهل الوزارة للخليفة المأمون ويعبر عن ذلك كل من الطبري والجهشياري إذ يذكرا : (أن أرزاق الكتاب والعمال في زمان أبي جعفر ، للرؤساء ثلاثة مائة درهم للرجل ونخو ذلك ، وكذلك كانت في أيام بني أمية ، وعلى ذلك جرت إلى أيام المأمون ، فإن الفضل بن سهل وسع الجاري من أرزاق الكتاب والعمال في أيام المأمون(4)، وما كان منصب رئيس الكتاب في العصر الأموي يعادل منصب الوزير في العصر العباسي ، فمن المعتقد أن الوزير ظل حتى عصر الخليفة المأمون يتناول راتبا قدره ثلاث مائة دينار ، ومما لاشك فيه أن هذا التنظيم لم يكن ينطبق

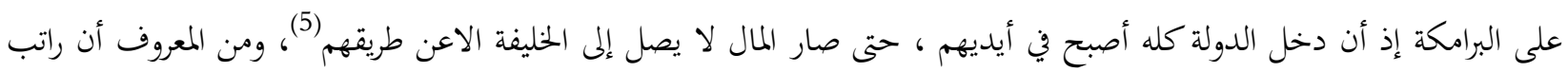
الوزير في الأندلس بلغ في إمارة عبد الرحمن الأوسط ثلاث مائة دينار (6) في الشهر الواحد (7).

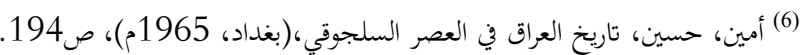

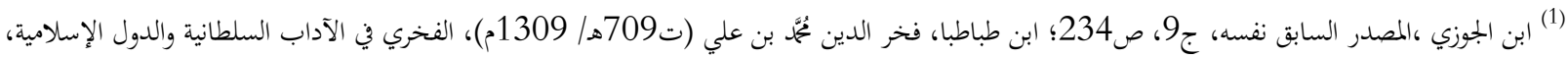

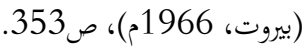

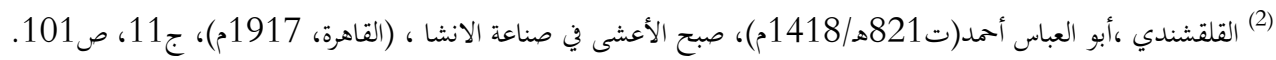

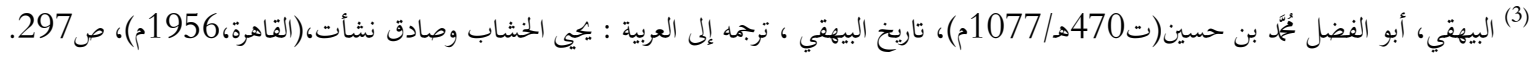

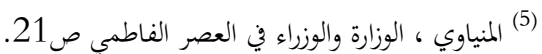

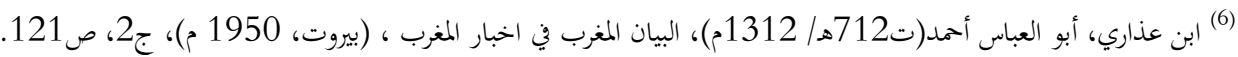

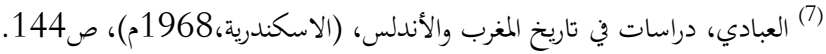




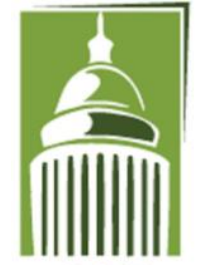

AR F
Global Proceedings Repository

American Research Foundation

ISSN 2476-017X

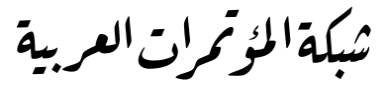

http://arab.kmshare.net/

Available online at http://proceedings.sriweb.org

ومع ذلك فإن هذا الراتب ضئيلا هزيلا إذ ما قارناه بما كان يتلقاه الوزراء في بغداد في العصر العباسي الثاني (8) فقد كانت أرزاق عبيد الله بن سليمان وزير الخليفة المعتضد ألف دينار في الشهر الواحد مضافا إليهما خمسمائة دينار لابنه القاسم ، وهو مبلغ يساوي مرتب ردب رئ وزير ، ثم زيد راتب الوزير حتى أصبح في خلافة المقتدر بالله خمسة الأف دينار ولكل ولد من أولاده خمسائة دينار ، وكان مرتب الابن يزداد في بعض الأحيان إلى ألف دينار. يضاف إلى هذه المرتبات الضياع والأراضي والعقارات التي كان يهبها الخليفة لوزيره أو التي كان يموزها لنفسه بطريقة أو بأخرى(1)، والتي كانت تصادر بالتالي عقب إقالته من الوزارة ، وكان ريع هذه الاقطاعات يصل إلى أكثر من خمسين ألف دينار في السنة ، حتى كان الوزير في بعض الأحيان يتنازل عن راتبه(2) على حين كان البويهيون يغدقون على وزرائهم من الاقطاع ما يدر عليهم خمسين ألف دينار (3). أما السلاجقة فجعلوا لوزرائهم عشر غلات البلاد، ولما أصبح للخلفاء حق اتخاذ الوزير بعد زوال السيطرة البويهية منح بعضهم إقطاعا ببضعة عشر ألف دينار(4)، أما في قرطبة في عصر الخلافة فقد كان أحمد بن عبد الملك بن شهيد وزير الخليفة عبد الرحمن الناصر يتقاضى راتبا يقرب من مائة ألف دينار في السنة وهو رقم كبير يتضمن الكثير من المبالغة(5)، وذكر المقري أن الناصر أضعف لابن شهيد رزق الوزارة فبلغ راتبه ثمانين ألف دينار أندلسية(6)أما في مصر الفاطمية فكان الوزير يتقاضى راتبا شهريا قدره خمسة آلاف دينار بخلاف عن الإقطاعات(7) ، ونلاحظ أن مرتب الوزير الفاطمي كان يماثل راتب زميله العباسي، وكان لكل من أخوة الوزير وأولاده مرتبات مقرة تتراوح بين مائتي وثلاثمائة دينار، وقد زيدت إلى خمسمائة دينار لكامل بن شاور، وهذه المرتبات لم تكن تصرف بمقابل

(ا) (المصدر السابق نفسه، ص144)

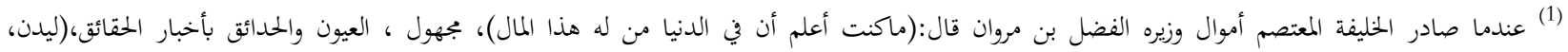

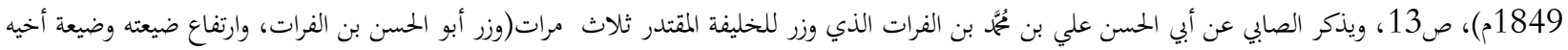

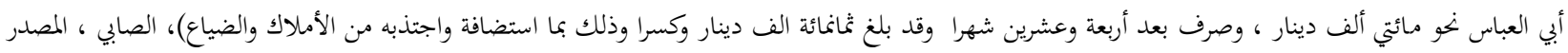
السابق نفسه، ص157.

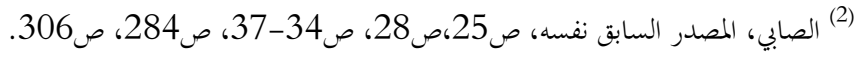

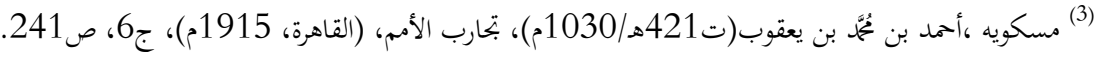

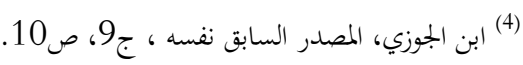

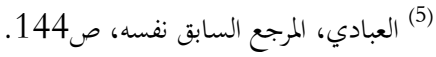

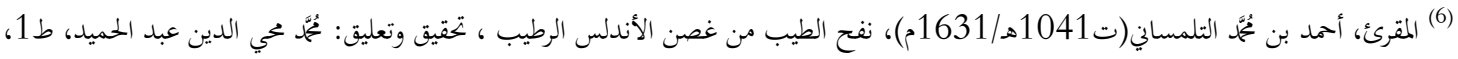

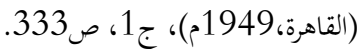

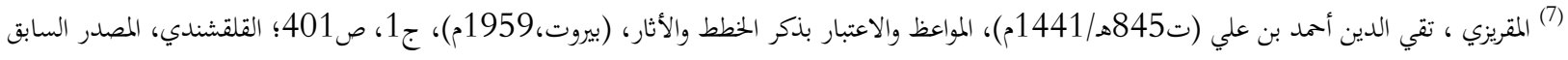




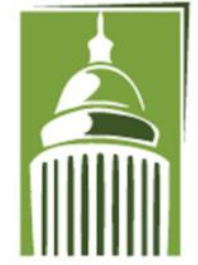

AR F
Global Proceedings Repository

American Research Foundation

ISSN 2476-017X

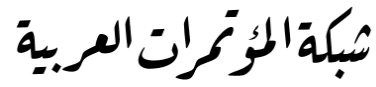

http://arab.kmshare.net/

Available online at http://proceedings.sriweb.org

عمل يقومون به بل بحكم صلتهم بالوزير، فإذا ما أسند لأحدهم أي عمل تقاضوا عنه أجرا علاوة على ما هو مقرر لهم وكثيرا ما منح

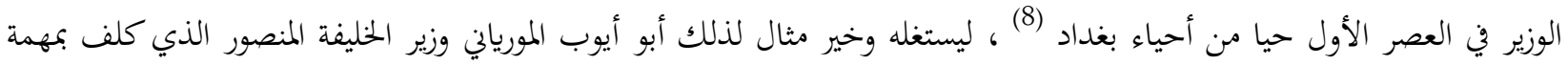
تنظيم أحد أحياء بغداد الأربعة وبدون شك كان بعضه إقطاعا عليه وقد سارت الأمور على هذا النحو حتى أقالته ، وقد قطع الربيع ابن يونس من ناحية أخرى حيين من أحياء بغداد كلف هو الآخر بتنظيمها ، وأقام الربيع بن يونس في أقطاعاته حوانيت وأسواقا في

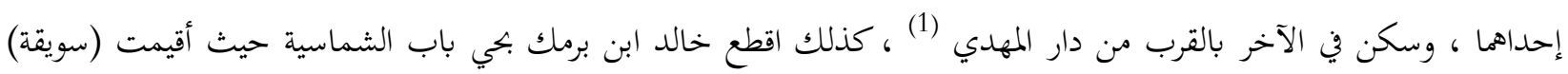
تحمل اسمه، ومنح بعض الوزراء مقام جديدا مثل سامراء ، ومثل ذلك الوزير ابن الزيات وبعض من تولى الوزارة قبله ومنهم الفضل بن

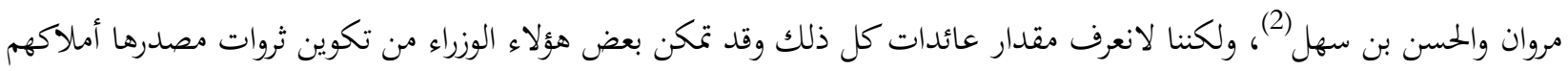

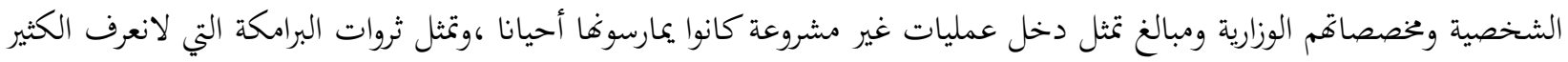
عنها هذا النوع من الثروات خير تثتيل ومن جهة أخرى فقد تبدت هذه الثروات سريعا لبذخ الوزراء وكرمهم ومرؤتم بحاه مواليهم وتحاه رجال الحاشية والأمراء وحتى بحاه الخليفة نفسه وكانوا يقيمون ولائم فاخرة ويقدمون لمدعويهم هدايا كما أنفق الوزراء أموال طائلة في تشيد القصور ليظهروا بمظهر المعمرين، وكذلك شيد الوزراء عمائر فخمة تعبر عن عظمة الوزراء وما كانوا يتمتعون من ترف، ومثل ذلك دار البرامكة التي كانت مقامة بحي باب الشماسية ببغداد وكذلك القصر المشهور الذي بناه جعفر إلى الجنوب من دارهم وعلى

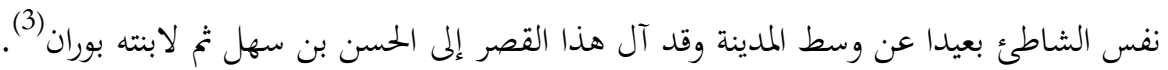
وبجمل القول أن تصرف الوزراء في دخولمم الشخصية أو الرسمية قد دعم مظاهر الهيبة والاحترام التي أحاطت منذ البداية بوظيفتهم والتي ازدادت تدريجيا على مر السنين كلما ازداد مركز الوزير ، فمن كاتب خاص للخليفة نجح الوزير في أن يرتفع إلى مرتبة مدير لأعماله ليصل مؤقتا إلى مكانه أعلى من مكانة الأمراء. المطلب الثالث: ألقاب الوزير.

ألقاب الوزير :اعتاد الخلفاء العباسيون منذ قيام دولتهم أن يمنحوا وزراءهم ألقابا فخرية (4)، فأبو سلمة الخلال وزير الخليفة أبي العباس

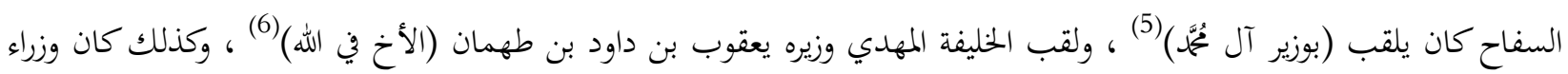

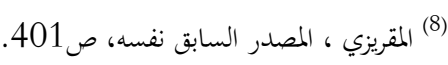

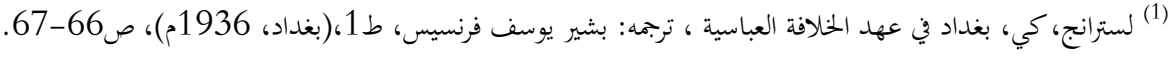

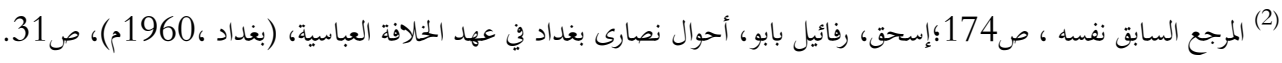

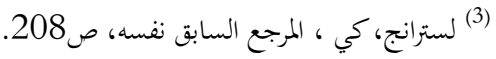

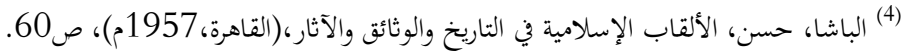




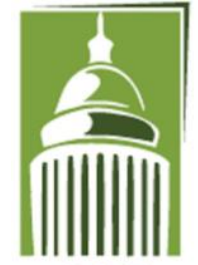

AR F
Global Proceedings Repository

American Research Foundation

ISSN 2476-017X

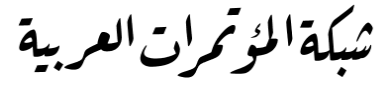

http://arab.kmshare.net/

Available online at http://proceedings.sriweb.org

الدولة العباسية يلقبون في أول الأمر بأمر الخلفاء بلقب (السلطان) على سبيل التفخيم وخير مثل على ذلك ما ذكره ابن خلدون من

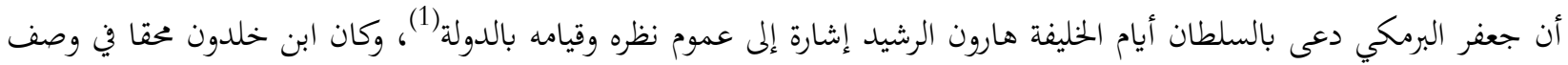
جعفر بالسلطان فقد بلغ في هذا المنصب الكبير ذروة السلطان فعلا. ومن الواضح أن لقب (السلطان) في هذه الحالة كان نعتا فخريا

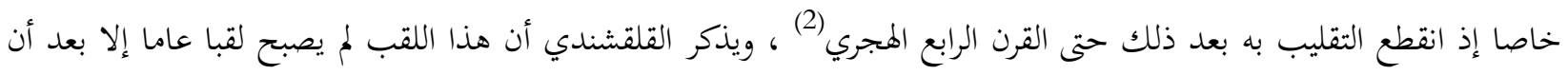
تغلب الملوك بالشرق مثل بنو بويه على الحلفاء واستأثروا بالسلطة دوفم وبذلك اتخذوا لقب (السلطان) سمة عامة لهم فضلا عما كان يضيفه عليهم الحليفة من ألقاب فخرية خاصة .ثم صار (السلطان) لقبا عاما على المستقلين من الولاة يضرب على نقودهم تمييزا لهم

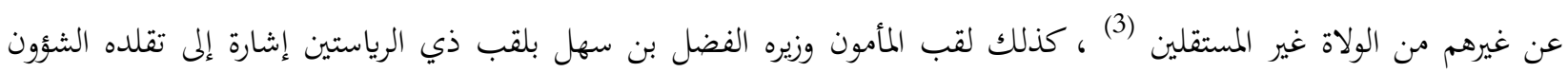

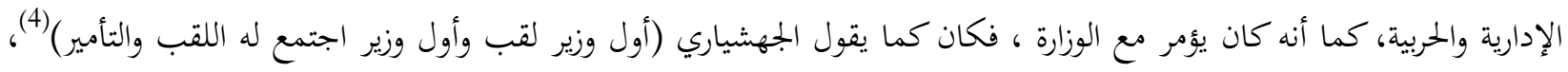
وقد عرف لقب ذي الرياستين في الأندلس لأول مرة في خلافة عبد الرمن الناصر منحه الخليفة لأممد بن عبد الملك بن شهيد ، والمراد من هذه التسمية أن يجمع صاحبها بين السلطتين المدنية والعسكرية في آن واحد وقد استعمل هذا اللقب أيضا في الدولة الفاطمية

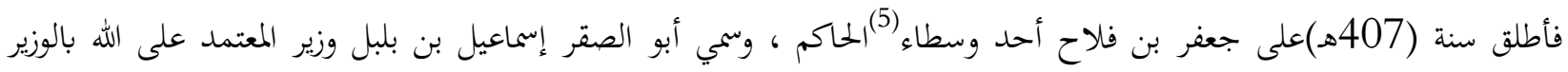
الشكور وجمع له أيضا السيف والقلم (6) كذلك أطلق الخليفة المأمون على وزيره الحسن بن سهل حين استوزره لقب ذا ذا الكفايتين (7)، ولكن الخلفاء العباسيين بعد ذلك أسرفوا في بذل الألقاب وقد ساعد على ذلك سوء الأحوال وفساد الأمور ومحاولة الخليفة إرضاء كبار رجال الدولة ويقول البيروني عن الإسراف في منح الألقاب وكثرةا (وبلغ الأمر غايته من التكلف والتثقيل حتى أن الذاكر لهم يميل

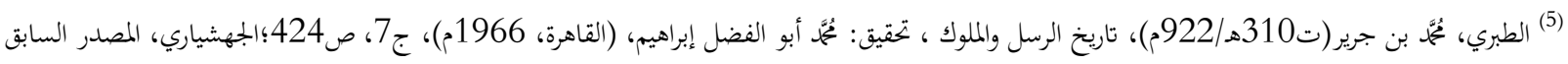

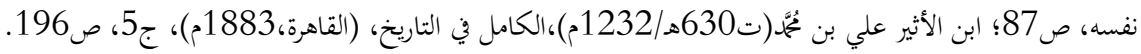

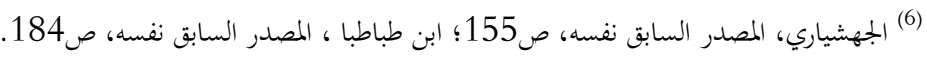

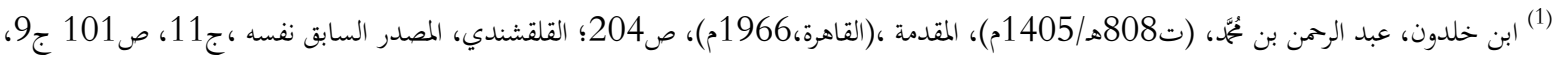

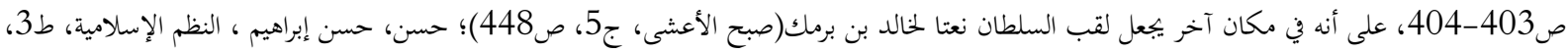

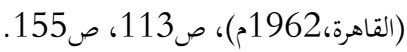

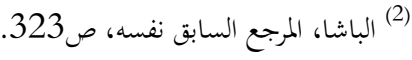

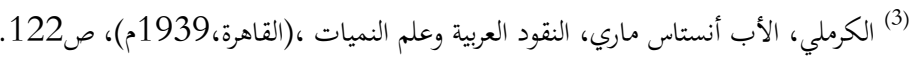

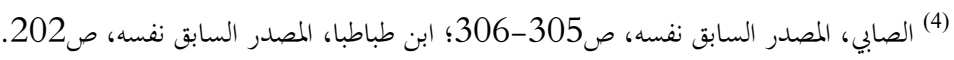

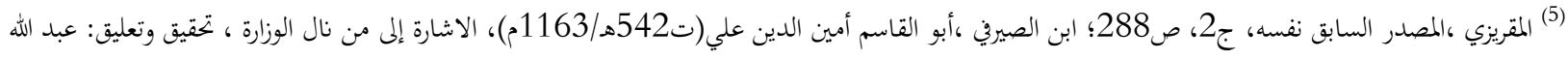

$$
\begin{aligned}
& \text { تخلص،(القاهرة، 1924م)، ص30-31-31. }
\end{aligned}
$$

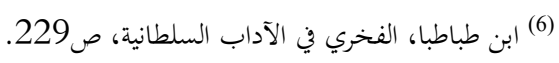




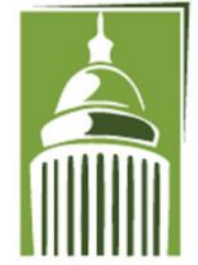

AR F
Global Proceedings Repository

American Research Foundation

ISSN 2476-017X

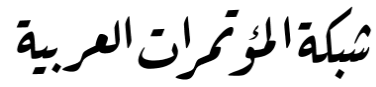

http://arab.kmshare.net/

Available online at http://proceedings.sriweb.org

ذكرهم قبل أن يتدئ به ، والكاتب يفني زمانا وأسطرا والمخاطب لم على خطر من فوت وقت الصلاة)(8) ، كما يقول أيضا عن وزراء الخلفاء أفم قد( لقبوا بالاذواء كذي اليمينين وذي الرئاستين وذي الكفايتين وذي السيفين وذي القلمين وأمثال ذلك ، وتشبه بهم آل بويه لما كانت الدولة منتقلة إليهم وبالغوا فيه واستغرقهم الكذب فسموا وزرائهم بكافي الكفاة الأوحد وأوحد الكفاة(1)، وقد حدث في الأندلس مثل ذلك عندما سقطت الخلافة بقرطبة وقامت دول الطوائف فتفنن الملوك في تمجيد خواصهم بالألقاب مثل لقب ذو الوزارتين وذو المجدين وذو السيادتين وذو الرئاستين ، دون أن تعني هذه الألقاب شيئا في حقيقة الأمر، أو كما قال ابن رشيق القيرواني:

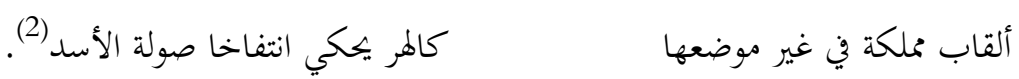
وبالإضافة إلى تكريم الخليفة وزيره بالألقاب ، فقد كان لهؤلاء الوزراء تكريم استثنائي ذلك أن يسك اسمه أو لقبه على العملة ولكن لم يظفر بهذا الامتياز إلا أفراد قلائل فلدينا جعفر البرمكي الذي كان له النظر على السكة فتمكن لذلك من أن يسك اسمه على بعض

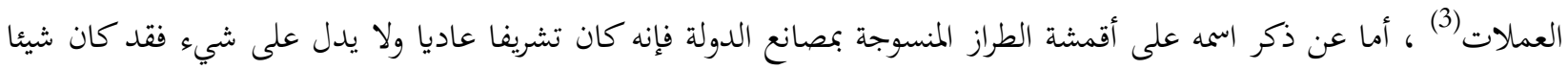

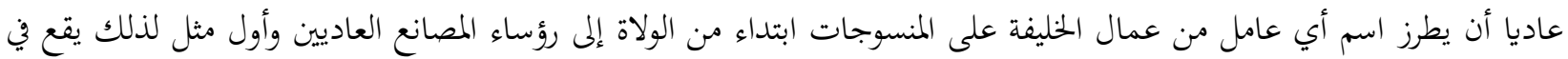
عهد الرشيد والأمين فقد سجل اسم الفضل بن الربيع على الطراز ، أما في القرن الثالث الهجري فإن العادة لم تجر بذلك اللهم إلى في عهد المتوكل، ونقرأ أحيانا في هذا النوع من النقوش لقب(مولى أمير المؤمنين) وهو لقب تحلى به الفضل بن الربيع وكان أبوه قد حمله من قبله ويككنا أن نقرب ذلك من التقليد الذي سار عليه الخلفاء فيما بعد وهو اعتبار الخلفاء بعض عمالم كموالي ، وبالرغم من قلة

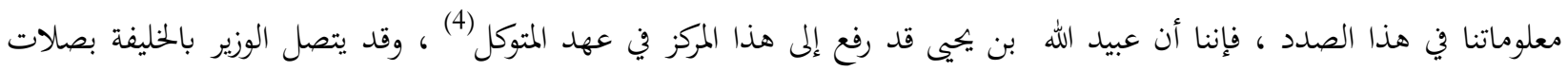
أوثق ، فقد قامت في العصر الأول ( إخوة في الرضاعة) بين أولاد الخليفة وأولاد الوزير وكان ذلك بصفة خاصة في عهد البرامكة ، فقد حدث أن أرضعت أم الرشيد (5) الفضل وأرضعت أمه الرشيد ، ومن جهة أخرى سمي يعقوب بن داود ( أخو الخليفة في الإيمان) (6) ،

$$
\begin{aligned}
& \text { (8) (8) الباشا، حسن، المرجع السابق نفسه، ص132. }
\end{aligned}
$$

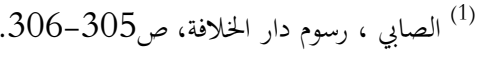

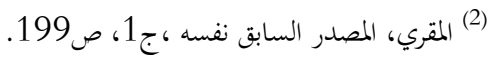

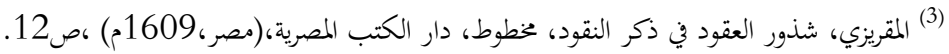

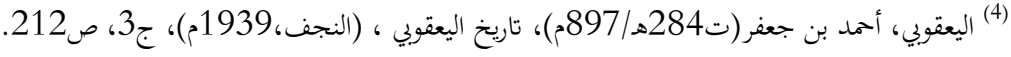

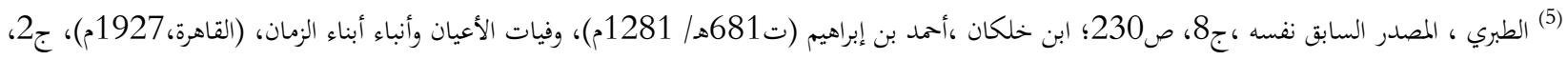

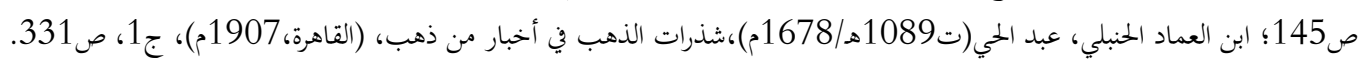

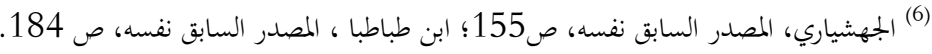




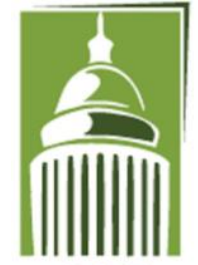

AR F
Global Proceedings Repository

American Research Foundation

ISSN 2476-017X

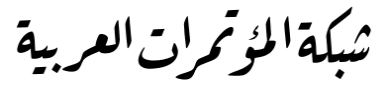

http://arab.kmshare.net/

Available online at http://proceedings.sriweb.org

وقد أعطى هذا اللقب نوعا من الحصانة لهذا الوزير الذي عرف أنه متشيع للزيدية وفيما بعد قامت علاقات مصاهرة بين عائلة الخليفة

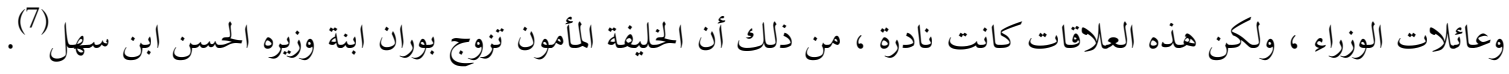
وأحيانا كان الخليفة يمتفي بوزيره ويشرفه بالزيارة إذا كان طريح الفراش نتيجة مرض أصابه، ويكون هذا نوع من التكريم، ومن أمثلة هذا

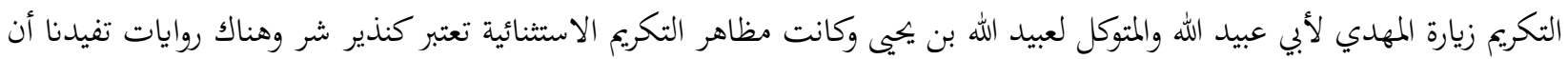
الوزراء الذين حظوا بتكريم استنائي كانوا يخشون بعده الجفاء أو العزل، وقد تلقى بعضهم نصائح بأن يتبعوا جانب الحذر ليحتفظوا بمراكزهم ، والواقع أن الإغداق على الوزير وتكريمه كان أسلوبا اتبعه الخلفاء أحيانا ليخفوا ما يبيتونه بشأنه، من ذلك أن الخليفة أبو

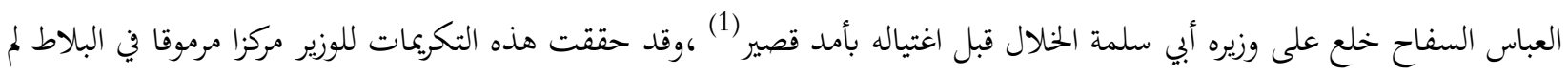
يصل إليه الكتاب اطلاقا، ولكن هذا النوع من النكريمات كان يمنح لغيره من كبار رجال القصر الخليفي من ذلك أن لقب ( ذو الرياستين) و(ذو الوزارتين) وهما لقبان متصلان بسلطان الوزير ، هذان اللقبان كان لما مرادف عسكرية فقد تلقب طاهر بن الحسين ( بذي اليمينين). وباستطاعتنا أن نقرب هذا من لقب (وزير آل يُمَّ) الذي لقب به أبو سلمة وكذلك لقب( أمين آل مُحّة) الذي حمله أبو مسلم الخراساني ، ويككنا القول بأن الوزير حتى وهو في ذروة سلطانه ، لم يكن الوحيد الذي يخظى بالتكريم فقد شاركه في مركزه

الأمراء والقواد الذين كان عليهم المحافظة على كيان الدولة (2).

المبحث الثاني: حياة الوزير.

المطلب الأول: زي الوزير: أما اللباس الرسمي للوزير في العصر العباسي فكان قوامه الدراعة وقميصا ومبطنة وخفا، والدراعة قميص مفتوح من الأمام إلى موضع القلب ومزين بالزراير النفيسة (3).

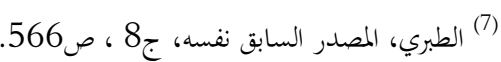

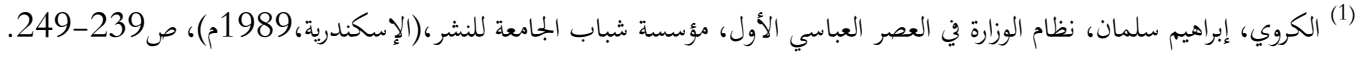

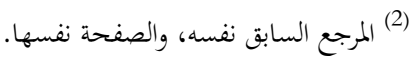

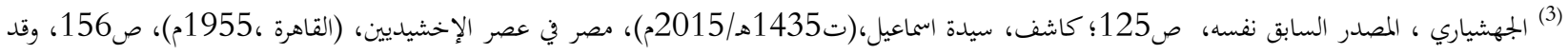

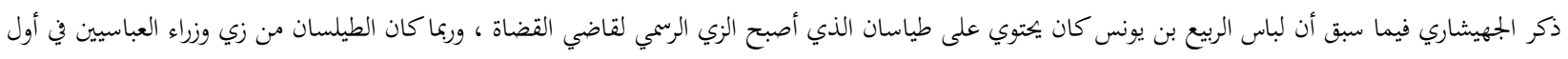

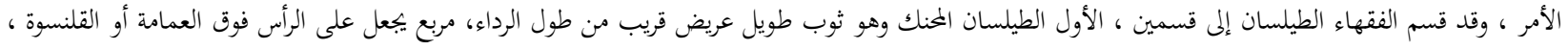

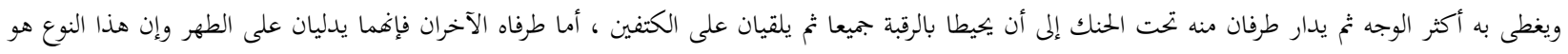

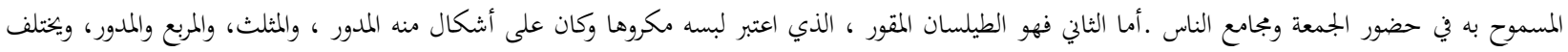




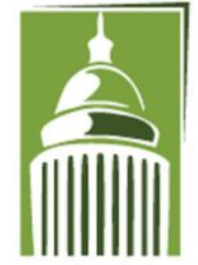

AR F
Global Proceedings Repository

American Research Foundation

ISSN 2476-017X

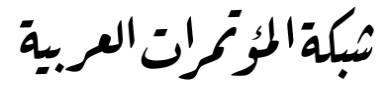

http://arab.kmshare.net/

Available online at http://proceedings.sriweb.org

كذلك كان الوزير يضع على رأسه العمامة(4) التي أصبحت في العصر العباسي من جملة الملابس الرسمية ولذلك أصبح لبسها مخورا

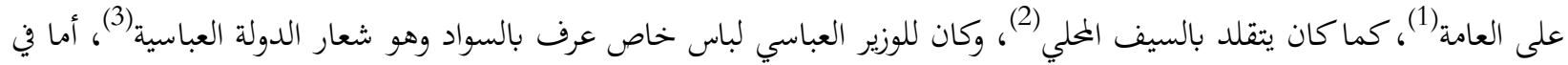
أيام الاحتفلات الرسمية فكان الوزير يرتدي ثياب المواكب وهي قباء وسيف بمنطقه، ومع هذه العمامة السوداء ، وهي الجزء الذي لا

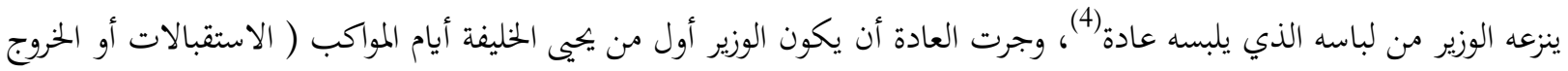
من القصر) ويرافق الوزير الخليفة أحيانا عند ذهابه إلى المضمار ( الحلبة) ، كذلك كان يسير في المواكب الرممية لأولاد الخليفة وعندئذ يسير إلى يمينه ورئيس الشرطة على يساره بينما يسير الحاجب في المقدمة، وكان للوزير الحق في أن يتحدث إلى المليفة على أثثر أي استقبال رسمي وأن يتلقى تعليماته ويسجلها (5). المطلب الثاني: دار الوزير.

وكان الوزير يتخذ داره في أفضل بقعة من بغداد وحتى سنة (320ه)، كانت هذه الدار هي نفسها التي كانت تنتمي قديما إلى

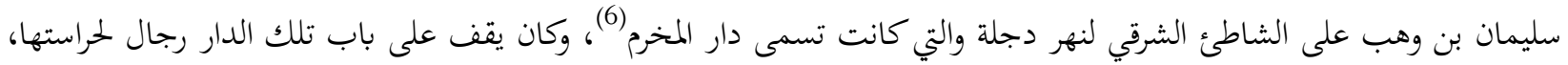
وقد بلغ من كثرةم أنه كان ربما يسحب منهم ثلاثون رجلا في وقت واحد يكلفون بهمة، أما في داخلها فكان هناك غلمان مسلحين

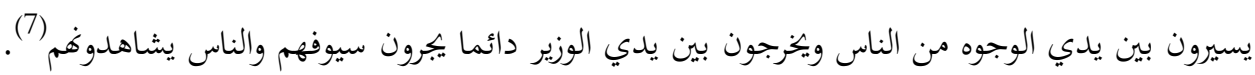
المطلب الثالث: مقر عمل الوزير. أما بالنسبة إلى مقر عمل الوزير فيشير الصابي إلى أن من رسوم الوزارة أن تكون للوزير دار مفردة في دار الخلافة يجلس فيها وينظر في

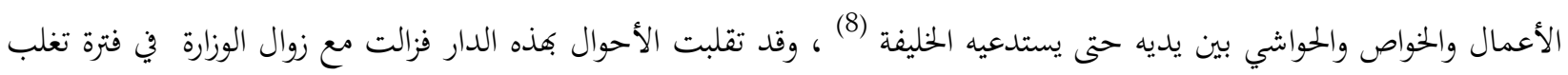

هذا الطيلسان عن سابقه في كونه يوضع على الرأس ويرسل طرفاه على الصدر دون أن يدار من تحت الحنك ويلفا حول الرقبة ، كما أن طرفيه المكفوفين يرسلان من وراء

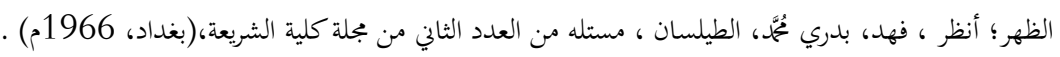

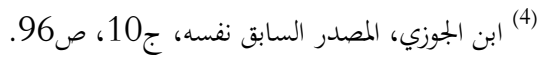

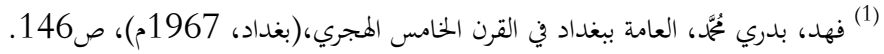

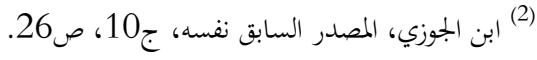

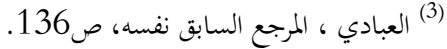

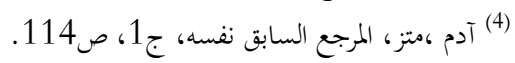

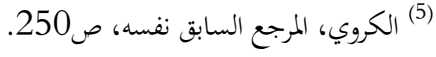

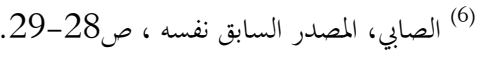

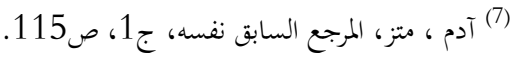

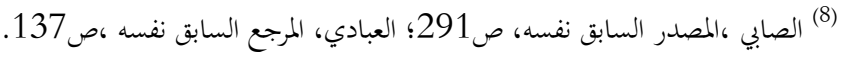




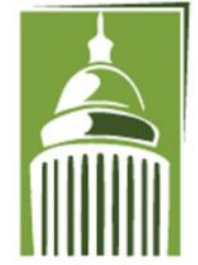

AR F
Global Proceedings Repository

American Research Foundation

ISSN 2476-017X

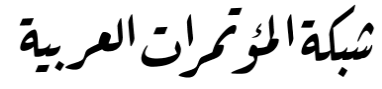

http://arab.kmshare.net/

Available online at http://proceedings.sriweb.org

البويهيين ولما استعادت الوزارة مكانتها جلس الوزير في هذه الدار مره أخرى فكان عون بن هبيرة(9)يجلس في الدار التي بباب العامة وجلس فيها ابن البلدي عند توليه الوزارة (1)، وكان يساعد الوزير في أعبائه عدد من الكتاب يملي عليهم بعض أعماله المراد تنفيذها وكان لهم رئيس يجلس متقدما عليهم للإشراف والتدبير ، وإذا أراد الوزير أن يكتب كتابا بنفسه استقدمت له دواة لطيفة بسلسة يمسكها الوزير بيده اليسرى ويكتب باليد اليمنى(2). المطلب الرابع: مظاهر تشريف الوزير.

ويبرز الدور التشريفي للوزير من صيغة المراسلات التي أرسيت قواعدها في وزارة ابن الزيات(3) ، فقد حقد الوزير على إبراهيم ابن عباس لأنه لم يجيه بالتحية المناسبة، وطبقا للصولي فقد شغل الوزير في ذلك المكان نفس المرتبة التي كان يشغلها ولي العهد فاستعملت الصيغة التي كانت تستعمل لولي العهد في حالة الكتابة للوزير وهي نفس صيغة تحية الخليفة ولكن مع حذف (وبركاته)، واستعملت صيغة الغائب معه مع تلقيبه بلقبه مقرونا بدعوة أو بتمني كذلك دأب كبار موظفي القصر في الكتابة إليه مقدمين أنفسهم بأفم(عبيد له) وقد قام الخاقاني بإلغاء هذا الأسلوب ليزيد من شعبيته، وكان الوزير موضع احترام وتبجيل من جانب الحاشية ، وكان له كما رأينا الحق في موكب خاص فقد جرت العادة على أن يصحبه كبار الموظفين ورؤساء الجيوش والقضاة والكتاب عند انتقاله من داره إلى دار الخلافة، وكذلك صرح لخاصته بالدخول في مخادعه أثناء ارتدائه حلته الرسمية ولكن هذا كان يعرض المنصب لأخطار كبيرة إذ حدث أن أعفى الوزير من منصبه أو غضب عليه الخليفة ولم يكن يستطيع تفاديها إلا بدفع غرامة كبيرة ، وقد كانت لحظة ارتداء الوزير الحلة الرسمية هي

التي يختارها أصحاب الحاجات للتقدم بطلباقم (4). وقد أراد الفضل بن سهل وزير الخليفة المأمون فيما قبل أن يهيى استعمالا قديما ساسانيا في مرو فحين وجوده بالقصر اعتاد أن يجلس على (كرسي) فإذا أراد الانتقال لملاقاة الخليفة كان يحمل على أعناق الرجال وهو جالس على كرسيه ولكنه يتركه عندما يؤدي التحية للخليفة ولكن يعود ويجلس عليه حين يخاطب المأمون ، وطبقا للروايات فإنه كان ينتقل في القصر محمولا على أريكة(5) ، ويبدو مع

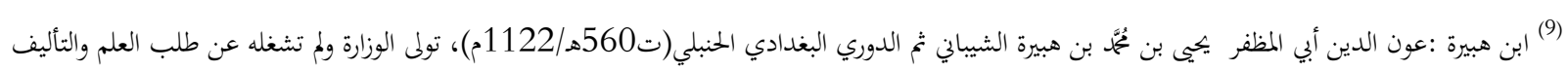

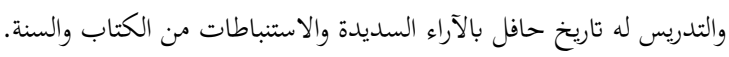

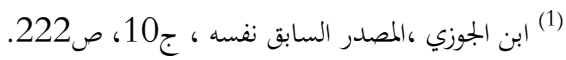

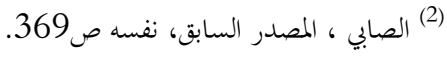

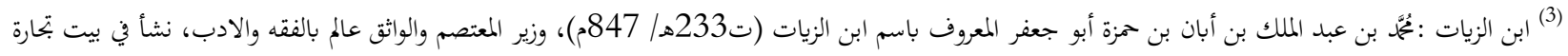
ونبغ وتقدم حتى بلغ رتبة الوزارة وعول عليه المعتصم في مهام دولته وكذلك الواثق.

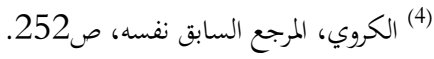

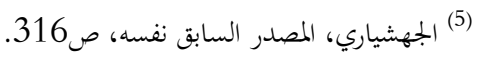




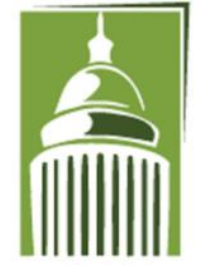

A R F
Global Proceedings Repository

American Research Foundation

ISSN 2476-017X
شبكة المؤرمَات العر.بة

http://arab.kmshare.net/

Available online at http://proceedings.sriweb.org

ذلك أن كل هذه الرسميات لم تترك أثرا في الفترة اللاحقة ، وقد كان للوزير حرس خاص إضافة إلى الخدم والحجاب الذين كانوا يحيطون به وخير مثال على ذلك حرس الوزير عبيد الله بن يميى وزير الخليفة المتوكل والذي بلغ عدده عشرة آلاف رجل منا أضفى عليه لقب( (أميرا) باعتباره وصيا على المعتز (1)

\section{الخايتمة}

يتضح لنا من هذه الدراسة أهمية نظام الوزارة في العصر العباسي الأول، كما حظوا الوزراء بقدر كبير من الهيبة والاحترام، ولم يكن الوحيد الذي يخظى بالتكريم فقد شاركه في مركزه الأمراء والقواد الذين كان عليهم المحافظة على كيان الدولة.

وقد توصلت الدراسة إلى نتائج منها. 1-بينت الدراسة أن هناك مراسيم خاصة كانت متبعة عند تقليد الوزير لمنصبه. 2-كشفت الدراسة أن على الوزير بعد جلوسه في دست الوزارة يقوم بإرسال كتاب إلى دار الخلافة يتضمن الدعاء والثناء للخليفة وإعلامه بعقوده وتسلمه منصبه. 3- وضحت الدراسة أن للوزير راتب شهريا يختلف باختلاف فترات هذا العصر وباختلاف الأشخاص، ولكل من أخوة الوزير وأولاده مرتبات مقررة. 4- بينت الدراسة أن تصرف الوزراء في دخولم الشخصية أو الرممية قد دعم مظاهر الهيبة والاحترام التي احاطت منذ البداية بوظيفتهم والتي ازدادت تدرييا على مر السنين كلما ازداد مركز الوزير. 5- وضحت الدراسة أن الخلفاء العباسيون اعتادوا منذ قيام دولتهم أن يمنحوا وزراءهم ألقاباً فخرية. 4-كشفت الدراسة أن للوزير العباسي لباس خاص عرف بالسواد وهو شعار الدولة العباسية. 6-بينت الدراسة أن للوزير دار يتخذها في أفضل بقعة من بغداد.

$$
\text { (1) المسعودي ،علي بن الحسين(ت346هـ/957م)،مروج الذهب ومعادن الجوهر ، (القاهرة،1915م)، ج2،ص393. }
$$




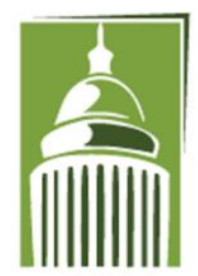

AR F
Global Proceedings Repository

American Research Foundation

ISSN 2476-017X

Available online at http://proceedings.sriweb.org

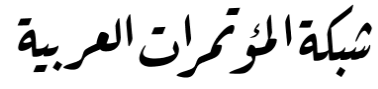

http://arab.kmshare.net/

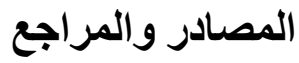

أو لا: المصنادر.

$$
\begin{aligned}
& \text { ابن الأثير، علي بن عُمَّمَ(ت630هـ/1232م). } \\
& \text { 1-الكامل في التاريخ،(القاهرة، 1883م). }
\end{aligned}
$$

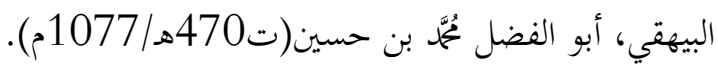

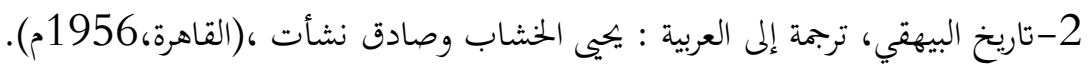

$$
\begin{aligned}
& \text { الجهشياري، ثُحَّم بن عبدوس(ت331هـ/942م). }
\end{aligned}
$$

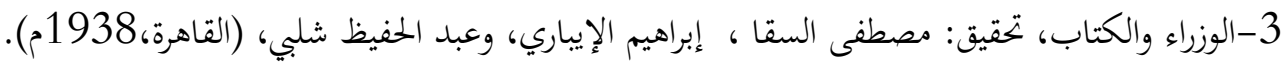

$$
\text { ابن الجوزي، عبد الرمن بن علي(ت597هـ/1200م). }
$$

4- المنتظم في تاريخ الملوك والأمم المنشور منه ابتداء من القسم الثاني من الجزء الخامس إلى فاية العاشرة باعتناء: الدكتور سالم

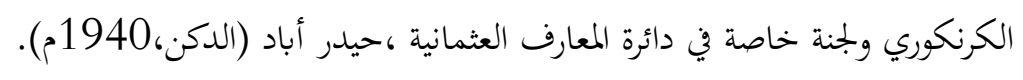

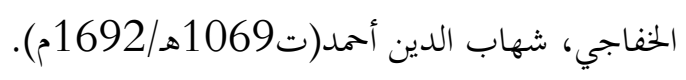

5- شفاء الغليل فيما كلام العرب من الدخيل، عني بتصحيحه: يُمَّمَ بدر الدين النعساني، (القاهرة، 1907م).

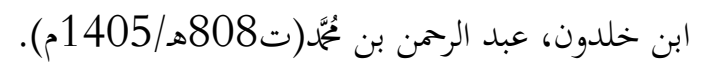

6- المقدمة ،(القاهرة، 1966م).

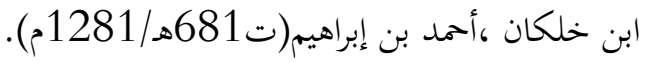

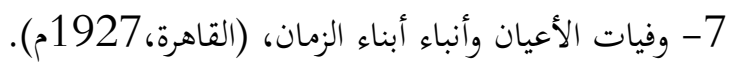

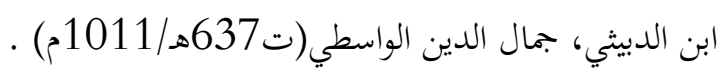




\section{Global Proceedings Repository \\ American Research Foundation}

ISSN 2476-017X

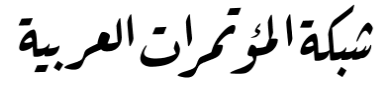

http://arab.kmshare.net/

Available online at http://proceedings.sriweb.org

$$
\text { 9- ذايل على ذيل تاريخ بغداد ،(خطوط دار الكتب المصرية، رقم } 3950 \text { تاريخ). }
$$

10- الوزراء أو تحفة الأمراء في تاريخ الوزراء ، تحقيق : عبد الستار أمد فراج،(القاهرة، 1958م).

11-رسوم دار الخلافة ، حققه وعلق عليه: ميخائيل عواد،(بغداد، 1964م).

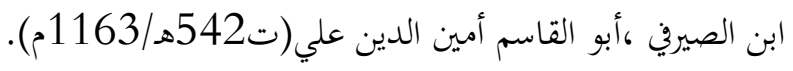

12- الإشارة إلى من نال الوزارة، تحقيق وتعليق: عبد الله مخلص ،(القاهرة، 1924م).

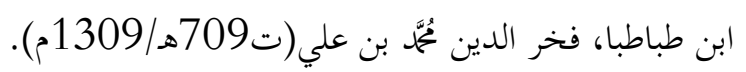

13-الفخري في الآداب السلطانية والدول الإسلامية،(بيوت، إن، 1966م).

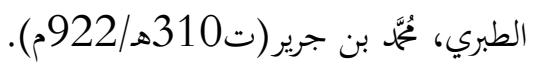

14- تاريخ الرسل والملوك، تحقيق: يُمَّمَ أبو الفضل إبراهيه،(القاهرة، 1966م). ابن عذاري، أبو العباس أممد(ت712 7ه/21312م).

$$
\text { 15-البيان في أخبار المغرب ، (بيروت، 1950م). }
$$

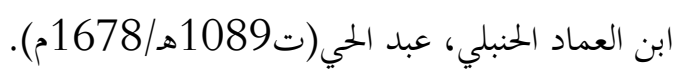

16- شذرات الذهب في أخبار من ذهب، (القاهرة، 1907م).

$$
\text { القلقشندي، أبو العباس أحمد(ت 821هـ/1418م). }
$$$$
\text { 17- صبح الأعشى في صناعة الانشا ، (القاهرة، 1917م). }
$$

18-العيون والحدائق بأخبار الحقائق،(ليدن،1849م).

$$
\text { المسعودي، علي بن الحسين(ت346هـ/957م). }
$$

19-مروج الذهب ومعادن الجوهر ، (القاهرة، 1915م).

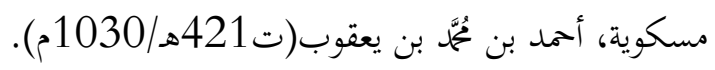




\section{Global Proceedings Repository \\ American Research Foundation}

ISSN 2476-017X

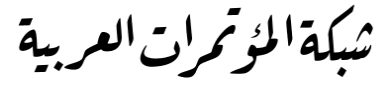

http://arab.kmshare.net/

Available online at http://proceedings.sriweb.org

$$
\begin{aligned}
& \text { 20- تجارب الأمم، (القاهرة،1915م). } \\
& \text { المقريزي، تقي الدين أحمد بن علي(ته45هـ/ 1441م) . } \\
& \text { 21-شذور العقود في ذكر النقود ، غخطوط ،دار الكتب المصرية،(مصر، 1609م). } \\
& \text { 22-المواعظ والاعتبار بذكر الخطط والآثار، (بيروت، (1959م). } \\
& \text { المقرى، أحمد بن يُمَّمَ التلمساني(ت 1041هـ/1631م). } \\
& \text { 23-نفح الطيب في غصن الأندلس الرطيب، تحقيق وتعليق: يُمَّم مي الدين عبد الحميد ، (القاهرة،1949م). } \\
& \text { اليعقوبي، أممد بن جعفر(ت284هـ/897م). } \\
& \text { 24-تاريخ اليعقبي، (النجف، 1939م). } \\
& \text { ثانيا: المراجع. } \\
& \text { إسحق، رفائيل بابو. } \\
& \text { 25- أحوال نصارى بغداد في عهد الخلافة العباسية ،بغداد، 1960م). } \\
& \text { أمين، حسين(ت1434هـ/2013م). } \\
& \text { 26-تاريخ العراق في العصر السلجوقي،(بغداد، 1965م). }
\end{aligned}
$$

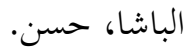

$$
\begin{aligned}
& \text { 27-الألقاب الإسلامية في التاريخ والوثائق والآثار،(القاهرة، 1957م). } \\
& \text { حسن، حسن إبراهيم 6. } \\
& \text { 28-النظم الإسلامية ، (القاهرة،1962). } \\
& \text { العبادي، أحمد مختار. } \\
& \text { 29-دراسات في تاريخ المغرب والأندلس (الإسكندرية، 1968م). }
\end{aligned}
$$

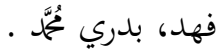

$$
\begin{aligned}
& \text { 30-الطيلسان مستله من العدد الثاني من مجلة كلية الشريعة،(بغداد،1966م). }
\end{aligned}
$$

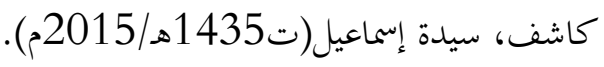




\section{Global Proceedings Repository \\ American Research Foundation}

ISSN 2476-017X

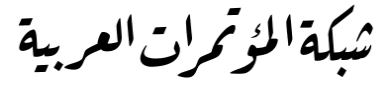

http://arab.kmshare.net/

Available online at http://proceedings.sriweb.org

$$
\begin{aligned}
& \text { 31-مصر في عصر الإخشيدين ،(القاهرة، 1955م). } \\
& \text { الكردي، إبراهيم سليمان. } \\
& \text { 32-الوزارة في العصر العباسي الأول، مؤسسة شباب الجامعة،(الاسكندرية، 1989م). } \\
& \text { الكرملي، الأب أنستاس ماري. } \\
& \text { 33-النقود العربية وعلم النميات،(القاهرة، 1939م). } \\
& \text { المنياوي، تُمَّمَ عبد الحميد. } \\
& \text { 34- الوزارة والوزراء في العصر الفاطمي بحث مقدم لنيل الدكتوراه في الآداب ،(جامعة الاسكندرية،1968م). } \\
& \text { ثالثا: المراجع الاجنبية المعربة. } \\
& \text { آدم 6متز . } \\
& \text { 35-الحضارة الإسلامية في القرن الرابع الهجري، نقله إلى العربية : عُمَّمَ عبد الهادي أبو ريده،(القاهرة،1947م). } \\
& \text { لسترانج، جي. } \\
& \text { 36-بغداد في عهد الخلافة العباسية ، ترجمة: بشير يوسف فرنسيس، (بغداد،1936م). }
\end{aligned}
$$

